\title{
IDENTIFYING AND RANKING THE CRITICAL SUCCESS FACTORS OF CHALLENGES IN PROVIDIENG QUALITY EDUCATION BY THE MALAYSIAN PRIVATE HIGHER LEARNING INSTITUTIONS
}

\author{
Rafikul Islam \\ Department of Business Administration \\ Kulliyah of Management Sciences and Economics \\ International Islamic University Malaysia (IIUM) \\ Jalan Gombak, 53100 Kuala Lumpur \\ E-mail: rislam@iium.edu.my \\ Azilah Anis \\ Centre of Transport and Operations Management \\ Faculty of Business Management \\ Universiti Teknologi MARA (UiTM) \\ 42300 Bandar Puncak Alam, Selangor, Malaysia \\ E-mail: azilahanis@salam.uitm.edu.my \\ and \\ Anisah Abdullah \\ Department of Business Administration \\ Kulliyah of Management Sciences and Economics \\ International Islamic University Malaysia (IIUM) \\ Jalan Gombak, 53100 Kuala Lumpur \\ E-mail: anisah@iium.edu.my
}

\begin{abstract}
The issue of quality education in higher learning institutions is timely and crucial due to the government's aspiration to turn Malaysia into a centre of educational excellence in the Asian region. Quality education acts as an indicator of the institution's ability to provide tertiary education to the society as well as an instrument for the nation's economic growth. Till date, numerous studies have been conducted in measuring the quality of education in higher learning institutions. However, the task in identifying the challenges faced by the institutions in providing quality education and the critical success factors to address those challenges are largely been ignored by previous researchers. Thus, by applying the mixed methods approaches, this study intends to identify and rank the challenges and critical success factors for each challenge. Data are collected from the Malaysian private higher learning institution's stakeholders for both stages namely; the qualitative and quantitative stage. Thematic analysis is utilised in identifying the challenges and critical success factors that gained through the semi structured interviews with the respondents. Subsequently, a survey is conducted to rank the identified challenges and critical success factors by employing the Analytic Hierarchy Process. At


ISAHP Article: Islam et al./ Identifying and Ranking the Critical Success Factors of Challenges in Providing Quality Education by the Malaysian Private Higher Learning Institutions

the end of the study, a framework to enhance the quality of education in Malaysian private HLIs is provided.

Keywords: quality education, challenges, critical success factors, higher learning institutions, Malaysia

\section{Introduction}

The Malaysian government's initiative in launching three educational acts in 1996 has resulted in increasing publicity and interest in Malaysia's educational sector development, specifically in its public and private higher learning institutions (HLIs). The National Council on Higher Education Act 1996, the Private Higher Educational Institutions Act 1996 and the National Accreditation Board, 1996, have also impacted liberalisation and internationalisation of the higher educational sector in Malaysia, enabling the transformation of Malaysia into a centre of educational excellence in the Asian region.

The task of the 20 public universities, 27 polytechnics and 59 community colleges and more than 450 private HLIs comprising university, university colleges, foreign universities and private colleges (www.moe.gov.my) is not only to accommodate the explosive growth of student enrolments in Malaysia but also to collaborate with the Ministry of Education (MOE) in realising the government's aspirations.

Developing Malaysia into a centre of educational excellence and internationalising Malaysia's higher education are major priorities for the MOE. As contended by Muhamad et al. (2006), the private HLIs play important roles in fulfilling the government's aspiration in transforming the nation into a centre of educational excellence in the region. The Tenth Malaysia Plan (2011-2015) also emphasises the significance of private HLIs as one of the instruments for driving the nation's economic growth. In particular, the Tenth Malaysia Plan targets to increase the GDP contribution from private HLIs by $2 \%$ and attract 150,000 international students by 2015 . And the vehicle to achieve this lofty objective is through maintaining a high standard of quality education, specifically those that are provided by the private HLIs (Muhamad et al., 2006).

Yet, it seems unlikely to achieve the above aspiration due to the negative reports and complaints pertaining to the quality of education in Malaysian private HLIs (Muhamad et al., 2006; Morshidi, 2006; Fahmi, 2006; The Star Online, 2007; Utusan Malaysia, 2008; The New Straits Times, 2010; The Star, 2011; The New Straits Times, 2012, and The Star, 2013). The high number of unemployed graduates resulting from their much to be desired employability skills and qualities (Woo, 2006), as well as the low numbers of qualified lecturers with $\mathrm{PhD}$ qualifications (Muhamad et al., 2006), are some aspects which point to the weaknesses of quality assurance systems in Malaysian private HLIs. Moreover, many different parties (Fion, 2009) are interested in how education should be run and a general lack of consensus as to the components that constitute quality education in HLIs (McNaught, 2003).

Fundamentally, the owners and administrators of private HLIs are struggling with limited resources and stiff competition to achieve the quality standards that have been established by the MOE and Malaysian Quality Assurance (MQA) (Yaakob et al., 2009). These Malaysian practitioners concur with the views of Belle (2009), Eric (2007) 
ISAHP Article: Islam et al./ Identifying and Ranking the Critical Success Factors of Challenges in Providing Quality Education by the Malaysian Private Higher Learning Institutions

and Donald (2003) that ensuring high quality standards in higher education constitutes one of the major challenges faced in order to remain sustainable in this highly competitive, global era. Yet, despite being acknowledged as one of the major challenges faced by HLIs, few researchers have attempted to explore the issue in depth.

Hence, by realizing this scenario, this study attempts to identify the most critical areas (challenges) and how such challenges should be solved (critical success factors) in providing quality education by Malaysian private HLIs to their stakeholders. By using the Analytic Hierarchy Process (AHP), these challenges and critical success factors are then assessed to determine their ranking and contribution in advancing the quality in Malaysian private HLIs.

\section{Literature Review}

\subsection{Quality education in higher learning institutions}

Defining quality in HLIs has proven to be a challenging task since researchers and practitioners have different views on quality in HLIs (Bornman, 2004). Furthermore as contended by Harvey and Green (1993), quality education is a term that is highly contested, considerably vague and highly contextual.

Nevertheless, three concepts have been identified in explaining quality education in HLIs. Firstly, it refers to the three elements of the educational system namely quality of input, quality of process and quality of output (Sahney et al., 2008). Input includes factors relating to students, teachers, administrative staff, physical facilities and infrastructure. The processes include activities of teaching, learning, administration and the outputs include examination result, employment, earnings and satisfaction. Secondly, that is related to functions and activities of HLIs such as all its functions and activities, curriculum, teaching faculty's qualifications, government, facilities, students' characteristics, management and administration as well as interactive networking (The World Declaration on Higher Education, 1998). The third approach which has gained prominence (Watty, 2005) is the concept of quality education in HLIs that is related to the stakeholders' approach. As affirmed by Vroeijenstijn (1991), it is advisable to define as clearly as possible the criteria that each stakeholder uses when judging quality education so that all these competing views are taken into account when assessing quality.

\subsection{Challenges in higher education institutions}

Belle (2009), Eric (2007) and Donald (2003) agreed that ensuring high quality standards in higher education constitutes as one of the major challenges faced by the HLIs for them to remain sustainable in this highly competitive, global era. Several issues with regards to the challenges in ensuring quality practices in HLIs are identified from the early studies. It includes leadership (Laurie, 2004, Sirvanci, 2004, Terry and Stanley, 2002), cultural and organizational transformation (Sirvanci, 2004, Ahmad et al., 2004 and Srikanthan and Dalrymple, 2003), program and curriculum (Philip and Danial, 2005), customer identification (Sirvanci, 2004), accreditation (Belle, 2009), faculty and other staff (Muhamad et al., 2006), financial (Philip, 2007; Sirvanci, 2004) and technological advancement (Sirvanci, 2004).

\subsection{Critical success factors (CSF) and quality practices in HLIs}

International Symposium on

the Analytic Hierarchy

Process
Washington, D. C. June 29 - July 2, 2014 
ISAHP Article: Islam et al./ Identifying and Ranking the Critical Success Factors of Challenges in Providing Quality Education by the Malaysian Private Higher Learning Institutions

The principle of CSF was proposed by Ronald Daniel in 1960 and achieved popularity in 1979 through the efforts of John Rockart. According to Rockart (1979), critical success factors (CSF) has a limited number of areas which, if satisfactory, will ensure competitive performance in organisations.

However, in the context of the present study, CSFs are the actionable solutions executed by the management of the institutions to address the challenges in providing quality education. The operationalising concept of CSF was taken from Owlia and Aspinwall (1997) who investigated the CSFs for TQM in HLIs in the United Stated and United Kingdom, as well as Islam (2010) who ranked CSFs for the challenges in achieving Malaysia's vision 2020. These researchers conceptualised CSFs as either the solutions to the problems encountered (Owlia and Apinwall, 1997) or the factors that must be implemented to successfully address the challenges (Islam, 2010).

\subsection{Analytic Hierarchy Process (AHP) and CSFs in quality practices at HLIs}

In the education industry, AHP methodology has become an increasingly useful tool in different decision making situations (Sipahi \& Timor, 2010). Even though previous researches have proven the acceptance of AHP as an effective tool in the educational sector, only few researches touched on the AHP application in educational quality management (Henny \& Jan, 2006). Number of few recent studies that incorporate the elements of educational quality management with AHP application are conducted by Yeşim Yayla and Ortaburun (2011), Anis and Islam (2011), Tsinidou et al. (2010), Umayal Karpagam and Suganti (2010), Lam et al.(2008) as well as Raharjo et al. (2007).

\section{Objectives}

Overall, the study intends to enhance quality education provided by Malaysian private HLIs through the following specific objectives:

1. To determine various challenges faced by the Malaysian private HLIs in providing quality education.

2. To ascertain the critical success factors of each challenge faced by the Malaysian private HLIs in delivering quality education.

3. To rank the challenges and critical success factors for each challenge faced by the Malaysian private HLIs in the course of providing quality education by using the Analytic Hierarch Process (AHP).

\section{Research Design/Methodology}

The present study adopts mixed methods approach in achieving its research objectives. The first stage involves the qualitative approach to identify the challenges of providing quality education by Malaysian private HLIs as well as to ascertain the critical success factors as the practical solutions in addressing the challenges. The second stage of data collection utilises the quantitative approach to rank the identified challenges and critical success factors that are previously determined in the qualitative stage.

The stakeholders of Malaysian private HLIs serve as the sample for the first stage of the study. The sample comprises 26 respondents ranging from the quality director of the institutions, authorised personnel in tertiary education related government agencies including the MOE and MQA, a member for the National Association of Private Educational Institutions (NAPEI), employees of the institutions such as the lecturers and administrative staffs, students, prospective employers of graduates as well as parents. As 
ISAHP Article: Islam et al./ Identifying and Ranking the Critical Success Factors of Challenges in Providing Quality Education by the Malaysian Private Higher Learning Institutions

suggested by Creswell (2011), thematic analysis is applied to analyse the data for the challenges and CSF to be identified.

For the second stage of data collection which is the quantitative stage, again data will be collected from the stakeholders of Malaysian private HLIs. A survey will be employed to obtain the information from the 100 respondents through structured interviews. An AHP questionnaire will be designed and utilised in obtaining the ranking of challenges and CSFs from these respondents.

\section{Data/Model Analysis}

Outcomes of this stage are in progress.

\section{Conclusions}

Developing Malaysia into a centre of educational excellence in the Asian region is an aspiration of the Malaysian government. However, this objective is unlikely to be achieved considering the negative complaints and reports pertaining to the quality education specifically in Malaysian private HLIs. This study consists of two stages; firstly the qualitative stage, it identifies the challenges faced by Malaysian private HLIs in providing quality education to the stakeholders as well as the critical success factors to address the challenges. Secondly, the quantitative stage where the Analytic Hierarch Process (AHP) will be applied to rank the challenges and CSFs to reflect the significance and contribution of these challenges and CSFs in advancing quality in Malaysian private HLIs.

\section{Key References}

Harvey, L., \& Green, D. (1993). Defining quality. Assessment and Evaluation in Higher Education, 18(1), 9-34.

Islam, R. (2010). Critical success factors of the nine challenges in Malaysia's vision 2020. Socio-Economic Planning Sciences, 44(4), 199-211.

Muhamad J., Chan H.C., Shahnon, S., \& Sibly, S.S. (2006). Enhancing quality of faculty in private higher education institutions in Malaysia. Higher Education Research Monograph, National Higher Education Research Institute, Monograph 9/2006.

Saaty, T.L. (2008). Decision making with the Analytic Hierarchy Process. International Journal Services Sciences, 1(1), 83-98.

Sahney, S., Banwet, D.K., \& Karunes S. (2008). An integrated framework of indices for quality management in education: a faculty perspective. A TQM Journal, 20(5), 502-519.

Sirvanci, M. (2004). TQM implementation; critical issues for TQM implementation in higher education. The TQM Magazine, 16(6), 382-386. 